\title{
CD56-enriched CD3-positive Donor Lymphocytes
}

National Cancer Institute

\section{Source}

National Cancer Institute. CD56-enriched CD3-positive Donor Lymphocytes. NCI

Thesaurus. Code C157500.

A population of CD3-positive lymphocytes expressing the CD56 surface antigen, with potential immunomodulating activity. Upon infusion of the CD56-enriched CD3-positive donor lymphocytes, these cells may facilitate the reconstitution of CD4-positive T-cells, regulatory T-cells (Tregs) and natural killer (NK) cells, which may reduce the incidence of post-transplant graft-versus-host disease (GvHD) following haploidentical stem cell transplant (SCT). CD56 is a transmembrane glycoprotein also known as neural cell adhesion molecule 1 (NCAM-1). 